\title{
AN EXPERIMENTAL STUDY OF TEMPERATURE-GRADIENT METAMORPHISM
}

\author{
By D. Marbouty \\ (Centre d'Études de la Neige, Établissement d'Études et de Recherches Météorologiques, \\ Direction de la Météorologie, Domaine Universitaire, B.P. 24, 38402 Saint-Martin-d'Hères, \\ France)
}

\begin{abstract}
The present study was carried out with a view to quantifying the effects of the main parameters of temperature-gradient metamorphism. Cold-room simulation tests showed crystal growth to be an increasing function of the temperature-gradient modulus with a lower limit of around $0.25 \mathrm{deg} / \mathrm{cm}$. This growth also proved to be a function of temperature itself reaching a maximum at around $-5^{\circ} \mathrm{C}$. Furthermore, the shape of depth-hoar crystals was also shown to depend on temperature and to resemble approximately that obtained when crystals are formed in the atmosphere. Temperature-gradient metamorphism is observed to take place at constant density. Increase in crystal size is a decreasing function of density with a lower limit of around $150 \mathrm{~kg} / \mathrm{m}^{3}$, below which destructive metamorphism occurs accompanied by packing (similar to ET metamorphism): the upper limit is situated at approximately $350 \mathrm{~kg} / \mathrm{m}^{3}$ and no depth-hoar crystals occur above this value. The series of cold-room simulations enabled a highly simplified model of crystal growth to be constructed.
\end{abstract}

RÉsumé. Une étude expérimentale sur la metamorphose de gradient. Cette étude a été menée dans le but de mettre en évidence l'influence quantitative, sur la métamorphose de gradient, des principaux paramètres dont elle dépend. Pour cela nous avons procédé à des simulations en chambre froide. Nous avons ainsi pu vérifier que le grossissement des cristaux est une fonction croissante du module du gradient de température avec une limite inférieure vers $0,25 \mathrm{deg} / \mathrm{cm}$. Ce grossissement est également fonction de la température elle-même avec un maximum vers $-5^{\circ} \mathrm{C}$. De plus la forme des cristaux de givre de profondeur dépend de cette même température et l'on retrouve approximativement les formes générales obtenues lors de la croissance des cristaux dans l'atmosphère. La métamorphose de gradient se déroule à densité constante. Le grossissement des cristaux est une fonction décroissante de la masse volumique avec une limite inférieure vers I50 $\mathrm{kg} / \mathrm{m}^{3}$ en dessous de laquelle il se produit d'abord une métamorphose destructive avec tassement (semblable à une métamorphose d'isothermie), et une limite supérieure vers $35^{\circ} \mathrm{kg} / \mathrm{m}^{3}$ au dessus de laquelle on n'obtient plus de cristaux de givre de profondeur. Toutes ces simulations nous ont permis de bâtir un modèle très
simple de grossissement des cristaux.

Zusammenfassung. Eine experimentelle Untersuchung der Metamorphose unter einem Temperaturgefälle. Die vorliegende Studie wurde unter dem Aspekt der Quantifizierung des Einflusses der Hauptparameter für die Metamorphose unter einem Temperaturgefälle angestellt. Simulierte Tests in der Kältekammer zeigten, dass das Kristallwachstum eine steigende Funktion des Moduls des Temperaturgradienten ist, deren untere Grenze bei etwa $0,25 \mathrm{deg} / \mathrm{cm}$ liegt. Dieses Wachstum erwies sich auch als Funktion der Temperatur selbst, mit einem Maximum bei etwa $-5^{\circ} \mathrm{C}$. Weiterhin liess sich zeigen, dass die Form der Kristalle von Tiefenreif ebenfalls von der Temperatur abhängt; sie ähnelt etwa der, die bei Kristallbildung in der freien Atmosphäre auftritt. Metamorphose unter Temperaturgefälle findet bei konstanter Dichte statt. Die Zunahme der Kristallgrösse ist eine abnehmende Funktion der Dichte mit einer unteren Grenze von etwa $150 \mathrm{~kg} / \mathrm{m}^{3}$, unterhalb derer eine destruktive Metamorphose, verbunden mit Setzung (ähnlich der isothermen Metamorphose) eintritt. Die obere Grenze liegt bei ungefähr $350 \mathrm{~kg} / \mathrm{m}^{3}$; die Serie der Simulationen in der Kältekammer erlaubte den Auf bau eines stark vereinfachten Modells für das Kornwachstum.

\section{INTRODUCTION}

The formation of depth hoar is a factor responsible for the destabilization of the snow-pack and is consequently one of the causes triggering large numbers of avalanches. Although the principle underlying this metamorphism is known, few quantitative data are available to predict its extent in relation to the meteorological conditions affecting the snow-pack. As a one-dimensional model of changes in the snow-pack was already available, showing how energy transfers take place at the interfaces and within the snow-pack in addition to simulating variations in temperature and density profiles, it was decided to complete it by including the aspect of crystal development and, in particular, the occurrence of depth-hoar crystals.

To do so, a series of cold-room simulation tests in order to monitor the effects of each parameter was decided upon. 


\section{Methodology}

The experiments were carried out in thermostatic simulation boxes the dimensions of which were $1.50 \mathrm{~m}$ in length, $0.70 \mathrm{~m}$ in width, and $0.60 \mathrm{~m}$ in height. A current of heated air in a compartment at the bottom of each simulation box comprised the heat source. Temperature in the compartment was thermostatically controlled to within $\frac{1}{10}$ of a degree Celsius. Another cold-source compartment at the top, ventilated and cooled by an evaporator, enabled temperatures to be varied from -5 to $-40^{\circ} \mathrm{C}$ and was thermostatically controlled to within one degree Celsius. Temperature within the snow was monitored by a vertical rod in the middle of the box fitted with a probe every two centimetres and by probes fitted to the sides of the box. The whole box was insulated by polystyrene panels $12 \mathrm{~cm}$ thick and the cold-room temperature was kept at the mean temperature of the heating and cooling compartments. The snow was separated from these compartments by thin metal plates. Two types of simulation box were used:

(a) a box without internal partitions in the case of experiments involving extremely precise temperature monitoring, thereby permitting repeated sampling and measuring;

(b) a box divided into ten thermally insulated compartments to enable several experiments to be conducted simultaneously, either by placing different snow samples in each compartment or by filling them differently in order to obtain different temperature-gradient readings in each box.

A diagram illustrating the first of these types of simulation box is shown in Figure $\mathrm{I}$.

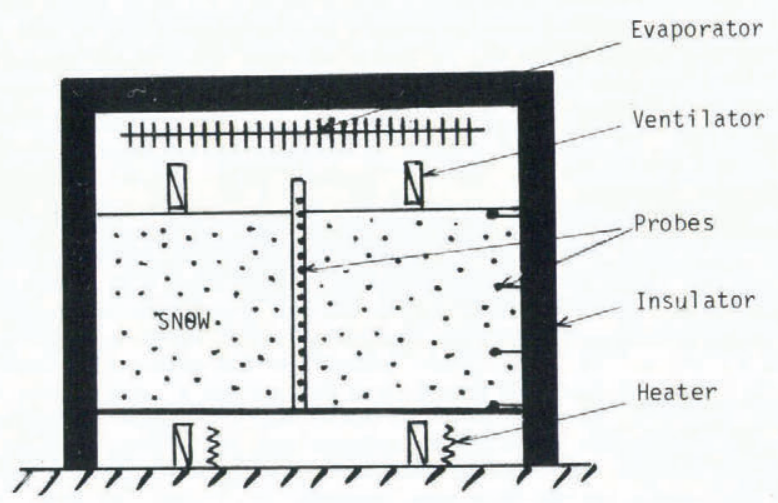

Fig. 1. Diagram showing a simulation box.

Monitoring of metamorphism development was mainly carried out by sampling and by macroscopic photography. Samples were taken using a core sampler capable of removing a cross-section of $7 \mathrm{~cm}^{2}$ over the total depth. Snow samples were subsequently subdivided into $2 \mathrm{~cm}$ sections for the purposes of analysis. This analysis consisted of a qualitative examination of the resulting crystals and of measurements of the mean diameter of the grains. These measurements, which were fairly rough, were obtained by photographing a sample and then dividing the total area by the number of crystals. Although this method has the disadvantage of disturbing the medium it enables crystal development to be closely followed.

Endoscopic observation was also attempted, since it does not disturb the medium to the same extent. However, observations are more difficult and not so precise, and this method was subsequently abandoned. 


\section{EFFECTS OF THE VARIOUS PARAMETERS ON TEMPERATURE-GRADIENT METAMORPHISM}

Temperature-gradient metamorphism consists of a series of sublimation and recrystallization processes between crystals, caused by imbalances in saturated vapor pressure arising from crystal temperature differences. It is therefore of thermal origin: the temperature gradient $\partial T / \partial z$ is negative under natural conditions. The value of this gradient will therefore have a considerable influence on the transformation. Other parameters, however, are also involved in the process, namely actual temperature $T$, density $\rho$, and the type of crystals initially present (these last two parameters being closely interrelated under natural conditions) which determine porosity.

\section{Effect of the temperature gradient}

The temperature gradient determines humidity gradients, inequalities in the degree of air saturation, and the diffusion rate of water vapour. When the same sample is subjected to different negative temperature gradients, crystal growth is found to increase with the modulus of this gradient $\partial T / \partial z$. A sample of fine-grained snow (mean size, $\bar{a}=0.2 \mathrm{~mm}$ and density

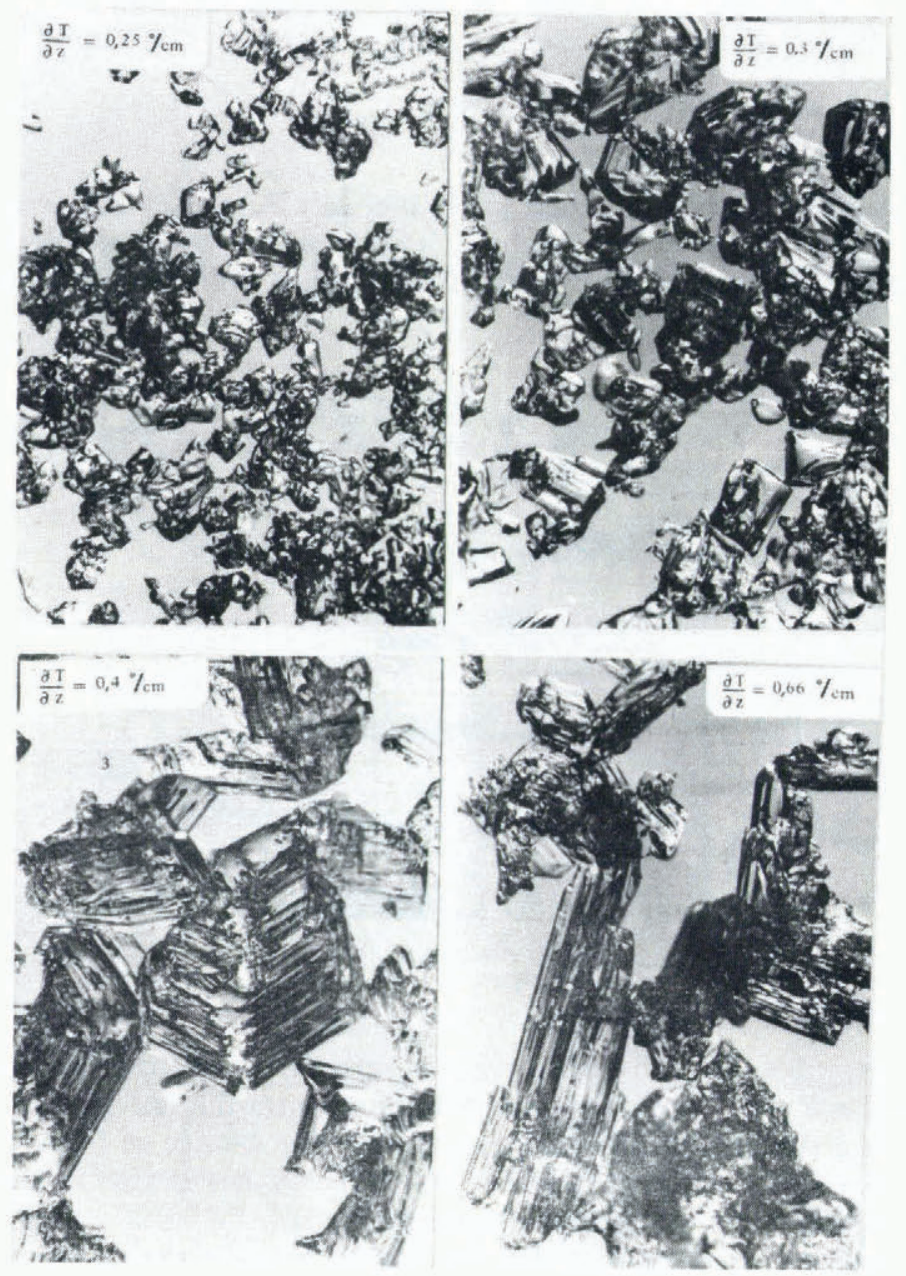

Fig. 2. Photographs of crystals obtained as a function of temperature gradient. 
$\rho=200 \mathrm{~kg} / \mathrm{m}^{3}$ ) when exposed to different gradients over a period of $26 \mathrm{~d}$ led to the results presented in Table I.

These results are further illustrated by Figure 2 which shows the crystals obtained at $-4^{\circ} \mathrm{C}$.

In addition, the series of experiments conducted revealed the existence of a threshold around $0.25 \mathrm{deg} / \mathrm{cm}$ above which metamorphism becomes truly significant. Below this threshold no TG grains are obtained and only sharp grains (represented by the symbol $\square$ ) are found, corresponding to the solid-type depth hoar reported by Akitaya (1974).

Table I. Mean grain diameter (in mm) after $26 \mathrm{~d}$ versus TEMPERATURE GRADIENT AT TWO DIFFERENT TEMPERATURE LEVELS

\begin{tabular}{|c|c|c|c|c|}
\hline & -0.25 & -0.3 & -0.4 & -0.66 \\
\hline-13 & 0.5 & 1.5 & 3.5 & 6.0 \\
\hline-4 & 0.8 & 2.0 & 6.0 & 8.0 \\
\hline
\end{tabular}

\section{Effects of density and initial snow type}

These two parameters were examined simultaneously since they are very closely related, as illustrated on Figure 3, taken from Pahaut (1975), which shows the density distribution versus grain type on the basis of observations made over five winters at the Col de Porte Laboratory.

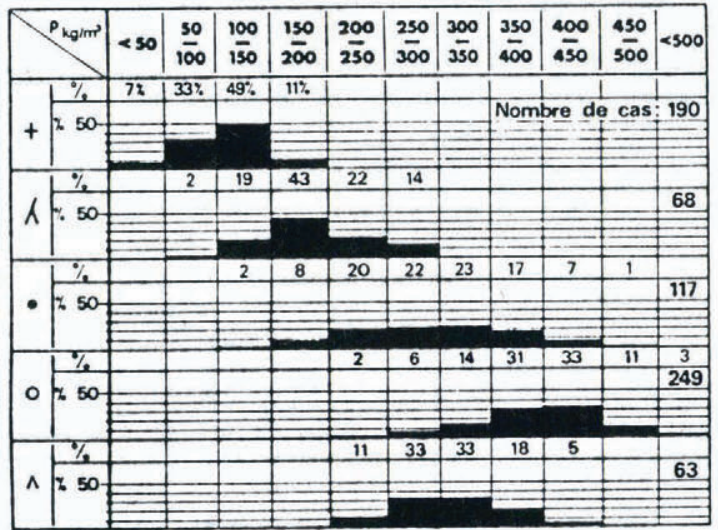

Fig. 3. Density distribution versus grain type.

The effect of snow densification on temperature-gradient metamorphism was consequently investigated and it was shown that this densification reduces the temperature-gradient metamorphism. Figure 4 shows that artificially increasing the density of a given sample of finegrained snow exposed to a constant gradient of $-0.55 \mathrm{deg} / \mathrm{cm}$ at two different levels over a period of $22 \mathrm{~d}$ resulted in two different temperatures, viz. -4 and $-18^{\circ} \mathrm{C}$. Densities were $\mathrm{I} 8 \mathrm{o}, 26 \mathrm{o}$, and $37 \mathrm{okg} / \mathrm{m}^{3}$. It is obvious that increase in crystal size is a decreasing function of density. 


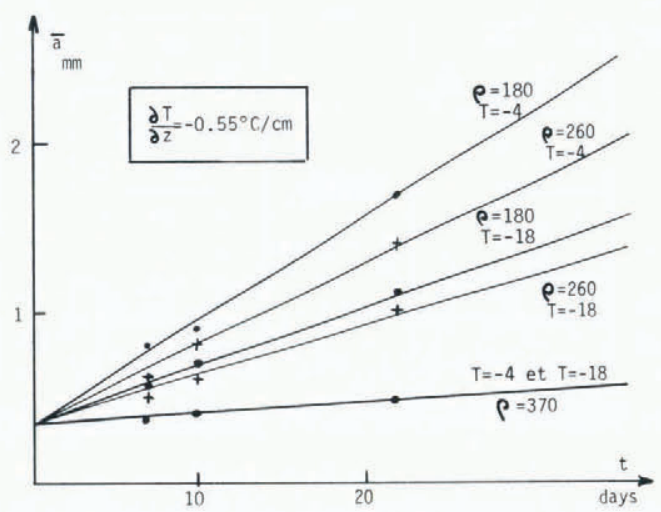

Fig. 4. Variation in grain-size versus initial density and temperature.

Insofar as the upper limit is concerned, very dense snow samples with densities exceeding $350 \mathrm{~kg} / \mathrm{m}^{3}$ (round grain types) vary little. Recrystallization occurs; round grains became sharp (symbolized by $\square$ ) but lack of space obstructs crystal growth. This obstruction was found to consolidate the snow mechanically, thus confirming Akitaya's observations with respect to hard depth hoar.

It was also observed that fresh snow, when subjected to a negative gradient, first undergoes destructive metamorphism (isothermal process) accompanied by packing, and subsequently metamorphism without packing. All simulations produced similar results with respect to this latter point; the depth of the snow within the box never varied during the experiments and, furthermore, direct density measurements taken at the beginning and end of experiments failed to show any variation. The preceding results are summarized by the diagram in Figure 5.

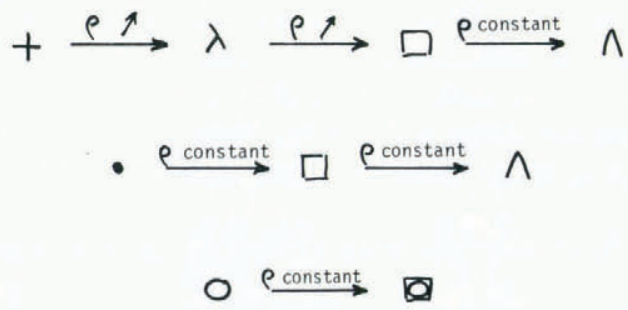

Fig. 5. Effect of temperature-gradient metamorphism versus the initial crystal.

The aforementioned results found for artificially densified snow samples, were again obtained when a naturally stratified snow sample consisting of layers of different density and grain type was subjected to a gradient of $-0.8 \mathrm{deg} / \mathrm{cm}$ for $20 \mathrm{~d}$. These results are presented in Figure 6. Note, however, that this sample was turned upside down owing to the method of sampling from the box, which explains why the denser layers of snow are found in the upper part of the sample.

\section{Effect of temperature}

Temperature influences metamorphism both in terms of its gradient and of its actual value $T$, which effects crystal size and determines their shape.

Roughly speaking, crystal size is a decreasing function of temperature, so that the largest crystals occur at the bottom of the layer. 


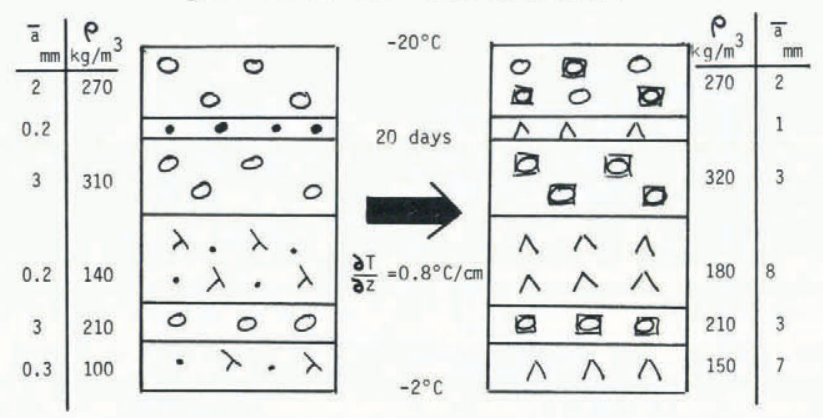

Fig. 6. Example of transformations of a naturally stratified sample.

The results of all the measurements that were taken are given in Table II. The largest crystals occur between -4 and $-8^{\circ} \mathrm{C}$; they are slightly smaller around $0^{\circ} \mathrm{C}$ and decrease notably in size beyond $-10^{\circ} \mathrm{C}$.

Table II. Crystal size (Relative value of mean diameter) versus temperature

$\begin{array}{cccccccccc}T^{\circ} \mathrm{C} & -3 & -5 & -6 & -8 & -11 & -14 & -17 & -20 & -22 \\ \frac{\bar{a}(T)}{\max (\bar{a}(T))} & 0.8 & 1.0 & 1.0 & 0.9 & 0.7 & 0.6 & 0.4 & 0.3 & 0.2\end{array}$

These values were determined with all other factors remaining unchanged. Obviously, this would not be applicable in the case of a cavity or other disturbing factor. The largest crystals, for instance, are found on top of the layer against the metal plate. This corresponds to the depth-hoar crystals that occur immediately below a layer of ice under natural conditions.

Temperature also affects the shape of TG grains. The photographs in Figure 7 show the characteristic shapes which were obtained during the simulation tests. These shapes are somewhat similar to those observed when snow crystals form in clouds or in surface hoar. This is due to the fact that the formation of depth hoar corresponds to a crystallization from the vapour phase and therefore obeys the general laws governing this type of phenomenon: these laws are equally applicable to both the formation of ice crystals in clouds and that of surface hoar on snow.

These general results have already been reported on a number of occasions (e.g. by Pahaut, 1975).

The following results were obtained with respect to depth hoar:

from -2 to $-5^{\circ} \mathrm{C}$, striated hexagonal shapes;

around $-6( \pm \mathrm{r})^{\circ} \mathrm{C}$, a characteristic needle zone;

from -7 to $-10^{\circ} \mathrm{C}$, hollow column-like shapes;

from - Io to $-25^{\circ} \mathrm{C}$, striated, hexagonal shapes, and plates.

On the other hand, crystals with dendrites are never found.

Hexagonal, plate-like, and pyramidal shapes are often found together. Furthermore, the plates appear to develop initially without any apparent striations; these gradually make their appearance as the crystal grows and run parallel to its six sides. Finally, they develop into ridges as illustrated by the photographs in Figure 8, which show samples at progressive stages of development. These macrosinpic striations are, however, typical of depth-hoar crystals.

Hallett and Mason (1958), studying the formation of crystals in clouds by means of a diffusion chamber, also found in $195^{8}$ that traces of organic vapour could modify considerably the nature of the resulting crystals. Traces of camphor, in particular, led to the formation 
$-3^{\circ} \mathrm{C}$
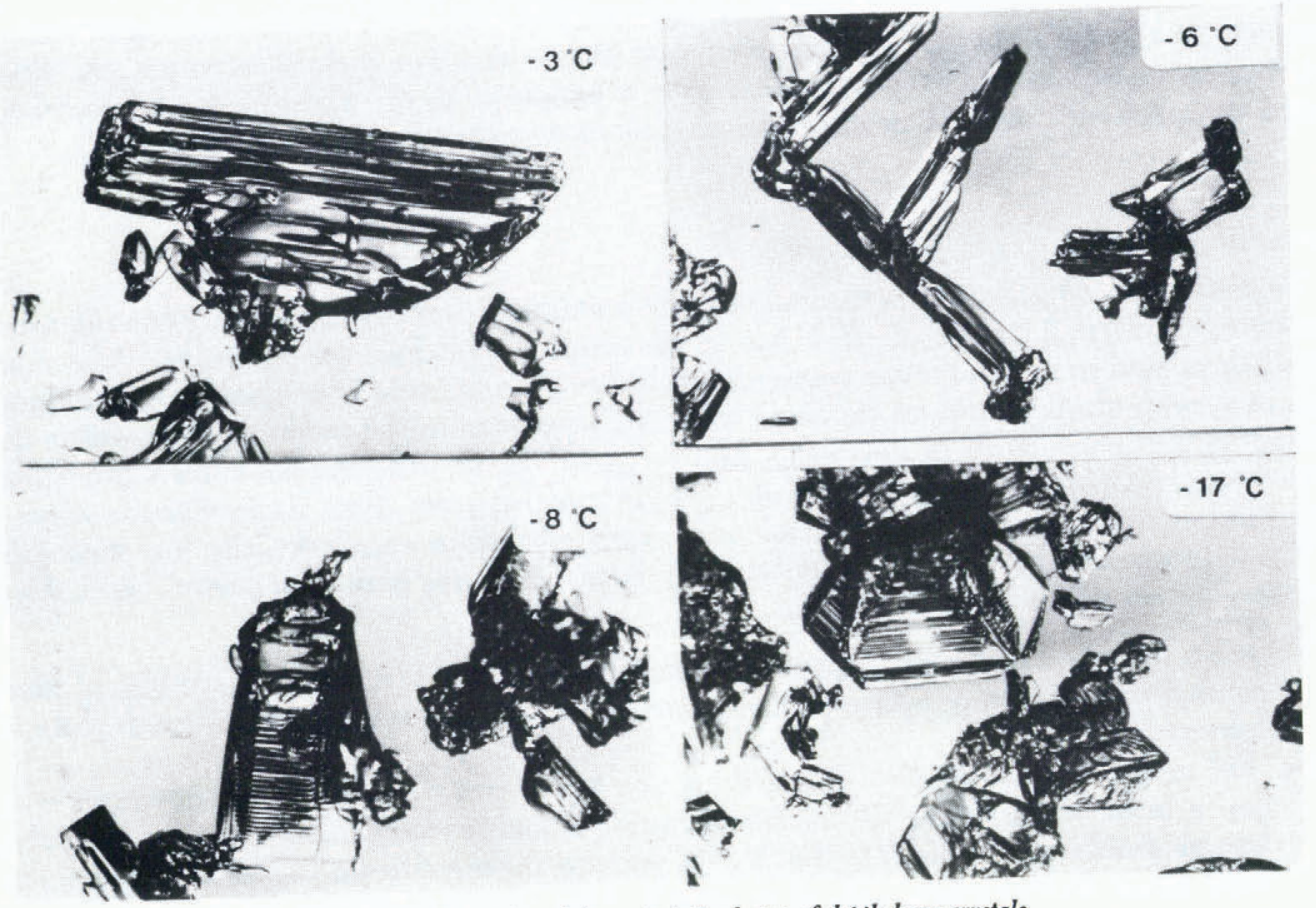

Fig. 7. Examples of characteristic shapes of depth-hoar crystals.
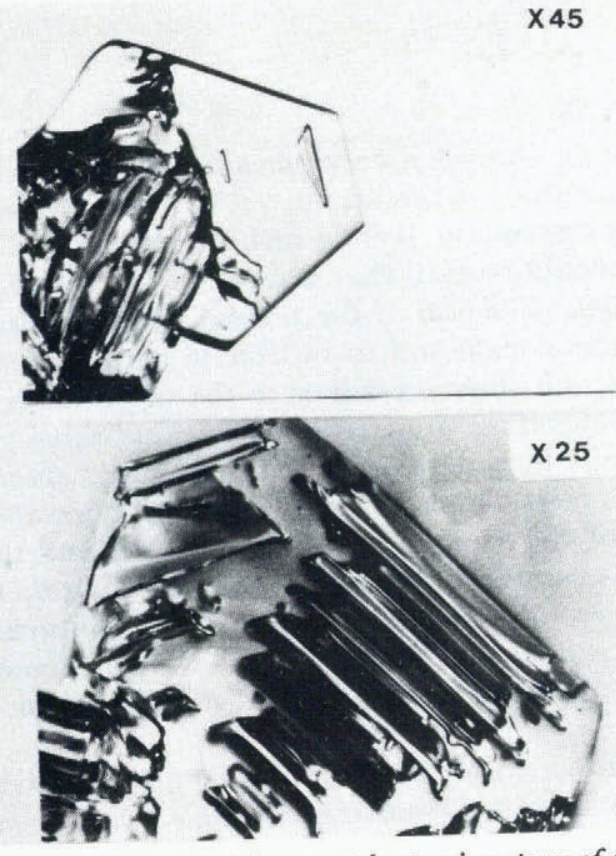

Fig. 8. Depth-hoar crystals at various stages of development showing the gradual appearance of striations. $\times 25$
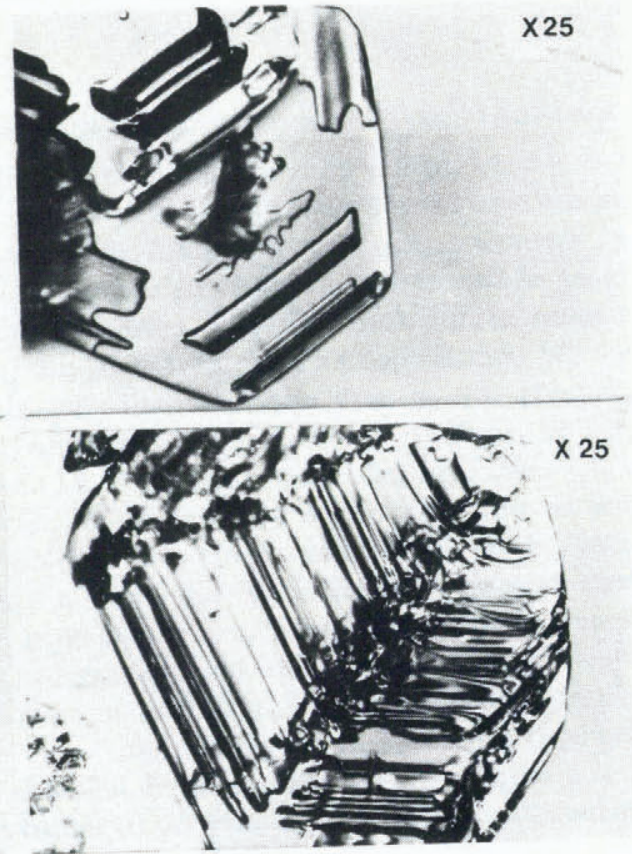
of needles at any temperature. In order to demonstrate that the formation of depth hoar is governed by the same laws, a little camphor was placed in a fine-grained snow sample which firmed the prepond to a negative gradient over a period of $15 \mathrm{~d}$. The results obtained confirmed the preponderance of needle-type crystals even at low temperatures $\left(-20^{\circ} \mathrm{C}\right)$.

\section{DEPTH HOAR UNDER NATURAL GONDITIONS}

To obtain an effective temperature-gradient metamorphism a steep gradient is required, therefore a limited thickness of snow has to be coupled with low temperatures. The most propitious period in terms of these requirements is early winter: relatively small depths of snow result in a steep gradient and, at the same time, the layer next to the ground is kept within the optimal temperature range of between o and $-\mathrm{I} 5^{\circ} \mathrm{C}$. These were the conditions prevailing in the French Alps during the winters of $1972-73$ and $1975-76$ (Rey, unpublished) when a large number of slab-avalanche accidents were reported despite an abnormally low snow-fall. The field work which was carried out during these two winter periods in particular enabled
the following observations to be made:

TG grain density was of a similar order of magnitude to that of fine grains (see Fig. 3), thus confirming that temperature gradient metamorphism in such fine grains takes place at constant density.

No TG grains with a density of less than $200 \mathrm{~kg} / \mathrm{m}^{3}$ were found. Note, however, that depth hoar of $\mathrm{I}_{50} \mathrm{~kg} / \mathrm{m}^{3}$ was obtained under laboratory conditions (see Fig. 6). This was probably due to the fact that initial packing during this particular simulation test took place more slowly and more gently than would normally be the case under
natural conditions.

Finally, no TG grains of high density were observed. This fact has significant practical implications: the tamping of ski slopes if carried out as from the first snow-fall prevents any temperature-gradient metamorphism from occurring.

\section{THE TEMPERATURE-GRADIENT METAMORPHISM MODEL}

It was not considered worthwhile to attempt to simulate all the phenomena involved by solving the set of equations which describes the diffusion of humid air, sublimation, crystallization, supersaturation phenomena, and possible convection. While such a model would not be devoid of theoretical interest, its complexity would be such that it would doubtless fail to prove more useful than a simple, empirical model. The aim of the present research was to predict the occurrence and the extent of the phenomenon and to be able to cumulate over long periods the growth effects which vary through time according to the parameters $T$, $\partial T / \partial z$, and $\rho$ which are considerably modified depending on meteorological conditions.

A numerical model (Navarre, 1974) had already been developed which simulates changes in snow on the basis of the meteorological parameters characterizing the atmosphere above the snow. This model first solves the problem of the snow-atmosphere interface and then proceeds to deal with heat and mass transfer and changes of state in the layers making up the snow-pack. While this model provides a good representation of temperature distributions in the snow, densification, melting, evaporation, and condensation, i.e. all the phenomena occurring at snow-strata level, it fails to account for processes taking place at grain level, and in particular, the formation of depth hoar.

So the empirical model developed below is intended to complete this numerical model.

Each snow type is defined only by its density $\rho$ and by the mean grain size $\bar{a}$. An attempt is made to predict the values of these parameters: $\rho(t)$ and $\bar{a}(t)$. 
It is assumed that transformation begins with fine grains of mean size $\bar{a}_{0}$ and density $\rho_{0}$. As far as $\rho$ is concerned, it was seen earlier that the curve follows simply:

$$
\rho(t)=\rho_{0} \text {. }
$$

The curve $\bar{a}(t)$ was defined empirically as:

$$
\bar{a}(t)=\bar{a}_{0}+f(T) g(\partial T / \partial z) h(\rho) \phi(t),
$$

where $f, g$, and $h$ are dimensionless functions from o to I and as simple as possible consistent with the experiments carried out.

The simulations carried out enabled the functions shown on Figure 9 to be proposed. The functions are found to be linear (for periods of less than $30 \mathrm{~d}$ ):
with
$\phi(t)=0.09 \mathrm{~mm} / \mathrm{d}$,
i.e.
$\phi(t) \approx \mathrm{I} \mu \mathrm{m} / \mathrm{s}$.
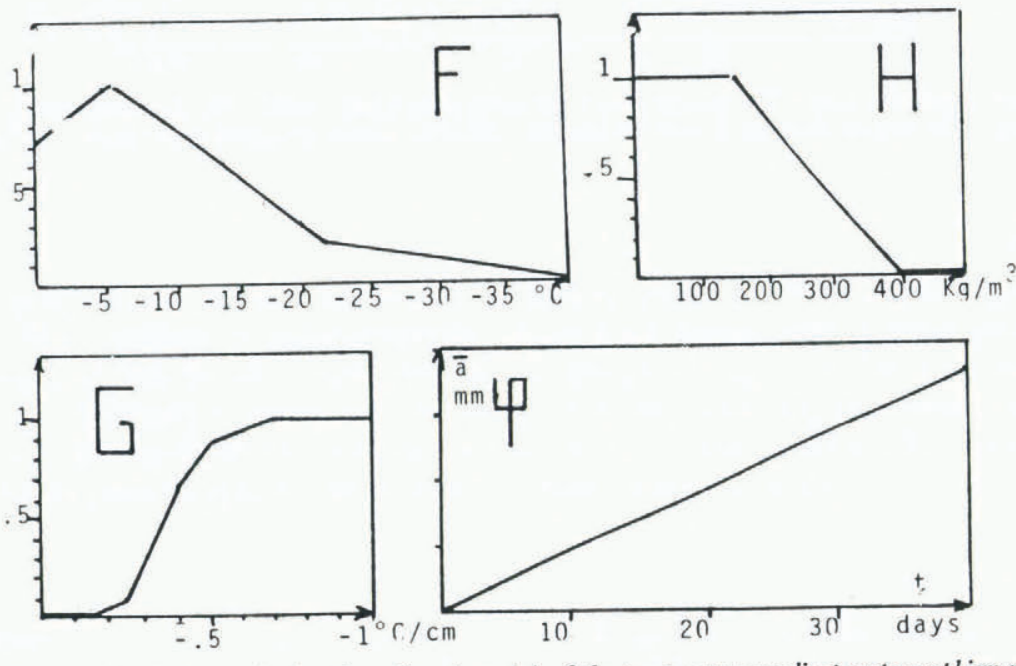

Fig. 9. Graphs depicting the functions $f, g, h$, and $\phi$ of the temperature-gradient metamorphism model.

It is worth noting that this value is of the same order of magnitude as those suggested by the linear growth curves of ice crystals found by Lamb and Hobbs (r97I). The functions $f$, $g$, and $h$ are therefore coefficients which take into account the values of the parameters affecting metamorphism.

In order to test the validity of the model, two simulation tests were subsequently carried out under conditions which differed slightly from those which had hitherto been used. The first of these tests involved a snow sample of $290 \mathrm{~kg} / \mathrm{m}^{3}$ subjected to a gradient of -0.45 $\mathrm{deg} / \mathrm{cm}$ for $34 \mathrm{~d}$. The second involved a sample of $230 \mathrm{~kg} / \mathrm{cm}^{3}$ subjected to a gradient of $-0.75 \mathrm{deg} / \mathrm{cm}$ over a period of $39 \mathrm{~d}$. The results of these two experiments are presented in Figure io. They are in good agreement with actual observations. Figure ro also shows the estimates of crystal size made by an observer. This evaluation tends to be on the high side and it is clear that the observer has estimated the size of well-developed TG grains rather than mean crystal size. On the other hand, it should be noted that the ratio of these estimates to the objective measurements of $\bar{a}$ was consistently of the order of $\mathrm{r} .6$. This is especially valuable since this type of evaluation is easily and quickly made and is particularly suitable for field work. 

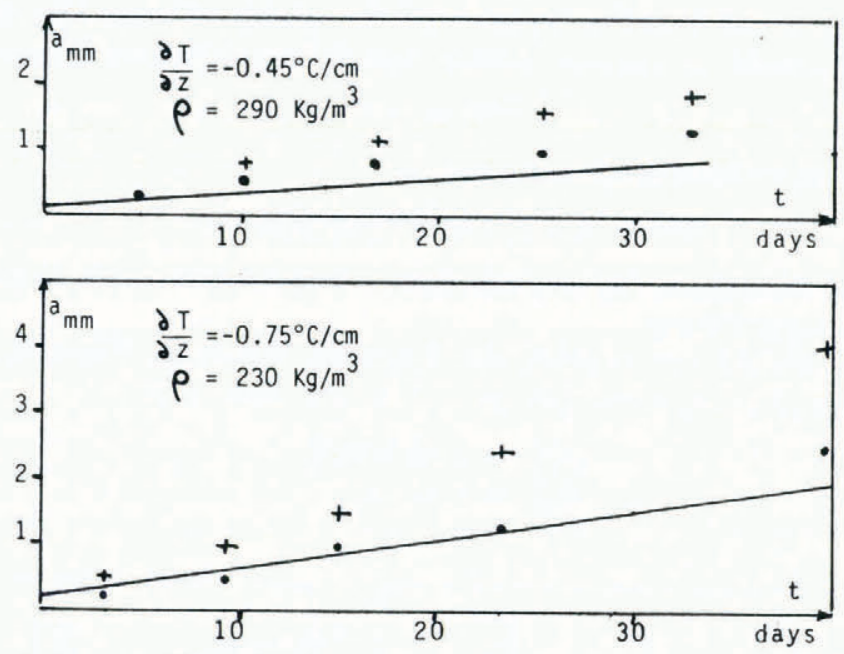

Fig. 1o. Results of simulation tests. The straight line is the result given by the model. The dots represent the measurements on each sampling. The crosses show the observer's estimates. All these results correspond to the level $-10^{\circ} \mathrm{C}$.

\section{Conclusions}

These recent experiments do not, of course, prove the validity of the proposed model, which is clearly only a very rough and ready approximation to reality. They are simply tests which seem to indicate that the model is fairly representative of the phenomenon. This work has also confirmed previous research results on temperature-gradient metamorphism, particularly those of Akitaya. Above all it has enabled the effects of gradient, temperature, and density parameters upon metamorphism, defined only by crystal size, to be quantified.

\section{Acknowledgements}

This research was conducted at the Centre d'Étude de la Neige in the laboratories located at Col de Porte and La Croix de Chamrousse, Isère, France, in the context of a contract executed on behalf of the Direction de la Sécurité Civile.

\section{REFERENGES}

Akitaya, E. 1974. Studies on depth hoar. Contributions from the Institute of Low Temperature Science, Ser. A, No. 26. Hallett, J., and Mason, B. J. I958. The influence of temperature and supersaturation on the habit of ice crystals grown from the vapour. Proceedings of the Royal Society of London, Ser. A, Vol. 247, No. 1251, p. 440-53.

Lamb, D., and Hobbs, P. V. 1971. Growth rates and habits of ice crystals grown from the vapor phase. Fournal of the Atmospheric Sciences, Vol. 28, No. 8, p. 1506-09. Navarre, J. P. 1974. Modèle unidimensionnel d'évolution de la neige déposée. La Météorologie, 1974, No. 3,
p. 109-20.

Pahaut, E. 1975. Les cristaux de neige et leurs métamorphoses. Monographie de la Météorologie Nationale, No. 96.

Rey, L. Unpublished. Météorologie et avalanches, les avalanches catastrophiques. [Thèse Concours Professionel, Météorologie Nationale, 1978.] 